\title{
Silver Nanoparticle-Coated Ethyl Cellulose Inhibits Tumor Necrosis Factor- $\alpha$ of Breast Cancer Cells
}

\author{
Ahmed AH Abdellatif $\mathbb{D D}^{1,2}$ \\ Mansour Alsharidah (iD ${ }^{3}$ \\ Osamah Al Rugaie (D) ${ }^{4}$ \\ Hesham M Tawfeek ${ }^{5}$ \\ Nahla Sameh Tolba ${ }^{6}$ \\ 'Department of Pharmaceutics, College \\ of Pharmacy, Qassim University, \\ Buraydah, 5I452, Saudi Arabia; \\ ${ }^{2}$ Department of Pharmaceutics and \\ Industrial Pharmacy, Faculty of Pharmacy, \\ Al-Azhar University, Assiut, 7I524, Egypt; \\ ${ }^{3}$ Department of Physiology, College of \\ Medicine, Qassim University, Buraydah, \\ 5I452, Saudi Arabia; ${ }^{4}$ Department of \\ Basic Medical Sciences, College of \\ Medicine and Medical Sciences, Qassim \\ University, Unaizah, AIQassim, 5I9II, \\ Saudi Arabia; ${ }^{5}$ Department of Industrial \\ Pharmacy, Faculty of Pharmacy, Assiut \\ University, Assiut, 71526, Egypt; \\ ${ }^{6}$ Department of Pharmaceutics, Faculty of \\ Pharmacy, Sadat City University, Sadat \\ City, Egypt
}

Introduction: Cancer is one of the leading causes of death worldwide. In many cases, cancer is related to the elevated expression of a significant cytokine known as tumor necrosis factor- $\alpha$ (TNF- $\alpha)$. Breast cancer in particular is linked to increased proliferation of tumor cells, high incidence of malignancies, more metastases, and generally poor prognosis for the patient. The research sought to assess the effect of silver nanoparticles reduced with ethyl cellulose polymer (AgNPs-EC) on TNF- $\alpha$ expression in MCF-7 human breast cancer cells.

Methods: The AgNPs-EC were produced using the green synthesis reduction method, and their formation was proofed via UV-VIS spectroscopy. Furthermore, AgNPs-EC were characterized for their size, charge, morphology, Ag ion release, and stability. The MCF-7 cells were treated with AgNPs-EC. Then, the expression of TNF- $\alpha$ genes was determined through PCR in real time, and protein expression was studied using ELISA.

Results: The AgNPs-EC were spherical with an average size of $150 \pm 5.1 \mathrm{~nm}$ and a zetapotential of $-41.4 \pm 0.98 \mathrm{mV}$. AgNPs-EC had an inhibitory effect on cytokine mRNA and protein expression levels, which suggests that they could be used safely in the fight against cancer. AgNPs-EC cytotoxicity was also found to be non-toxic to MCF-7.

Conclusion: Our data determined AgNPs-EC as a novel inhibitor of TNF- $\alpha$ production. These results are promising for developing novel therapeutic approaches for the future treatment of cancer with safe materials.

Keywords: silver nanoparticles, tumor necrosis factor- $\alpha$, ethyl cellulose, MCF-7 cells

\section{Introduction}

Cancer is an extremely threatening disorder which is spread all over the world. It needs rapid and effective treatment to decrease its severity and improve the patient's outcome finally. Undoubtedly, nanotechnology has a significant impact on finding numerous outstanding pathways to overcome this disorder and elevate conventional chemotherapeutic agents' drawbacks. ${ }^{1}$ Tumor necrosis factor- $\alpha$ (TNF$\alpha$ ) is a part of the TNF superfamily. It was the primary cytokine to be assessed for cancer biotherapy. In many studies, TNF- $\alpha$ was utilized systemically to control and treat solid tumors, but it has shown severe toxicities like severe hypotension and organ failure. A lot of evidence indicates that pathophysiological concentrations of endogenous TNF- $\alpha$ act to stimulate tumor genesis and growth. ${ }^{2}$ Generally, in breast cancer treatment, TNF- $\alpha$ plays a dual function as it may be a target and a medicine. TNF- $\alpha$ acquires both pro- and anti-tumor actions, conditional on the cellular
Correspondence: Ahmed AH Abdellatif Department of Pharmaceutics, College of Pharmacy, Qassim University, Buraydah, 5I452, Saudi Arabia

Email a.abdellatif@qu.edu.sa 
environment, tumor cell characteristics, and the TNF- $\alpha$ origin. TNF- $\alpha$ is produced physiologically in the tumor microenvironments by tumor cells and stromal cells. ${ }^{1}$

$\mathrm{TNF}-\alpha$ is responsible for the stimulation of natural mammary gland tissue proliferation, morphogenetic branching, and differentiation. TNFR1 is the receptor for the proliferation of typical epithelial cells, and TNFR2 modifies the casein build-up. ${ }^{3}$ Elevated TNF- $\alpha$ in blood serum has been reported in patients diagnosed with retarded breast cancer and is associated with increased metastatic site number and size. ${ }^{4}$ The elevated TNF- $\alpha$ level may have been related to the activation of nuclear factor kappa-light-chain-enhancer of activated B cells (NF-\#x1D6CB;B), which plays a vital role in carcinogenesis and inflammation. ${ }^{5}$ According to a study performed by Wenliang et al, ${ }^{6}$ the elevated TNF- $\alpha$ expression showed poor outcomes of using Sorafenib after surgery for hepatocellular carcinoma (HCC) patients. However, the invitro experiments indicated the function of TNF- $\alpha$ in promoting the HCC cell resistance to Sorafenib via stimulating epithelial-mesenchymal transition (EMT). The premetastatic role of TNF- $\alpha$ and its involvement in the EMT process essential for tumor cell migration to create metastasis have recently been shown in several studies. Prolonged exposure to TNF- $\alpha$ by breast cancer cell lines induces Twist1 upregulation by activating IKK $\beta$ and NF\#x1D6CB;B transcriptional repressor. It stimulates EMT and stem cell carcinoma. ${ }^{3}$ Another study mediated by $\mathrm{Wu}$ et $\mathrm{al}^{7}$ investigated if TNF- $\alpha$ could improve the effect of chemotherapy and radiology on breast cancer cells. The study confirmed that TNF- $\alpha$ presented radiotherapy- and chemotherapy-sensitizing impact against cells of breast cancer. TNF- $\alpha$ leads the cells out of phase G0/G1 and moves into the proliferation phase. Thus, after irradiation, TNF- $\alpha$ created more DNA damage and increased Docetaxel and Cisplatin-induced G2/M and S phase cell cycle arrest, respectively. Fehaid and Taniguchi examined the impact of silver nanoparticles (AgNPs) on the pulmonary epithelial cell's response to TNF- $\alpha$ as a molecular mechanism. The study showed increased cellular uptake of AgNPs was induced by TNF- $\alpha$ and low AgNP concentration increased the TNF- $\alpha$ protective effect against apoptosis. ${ }^{8}$ Amongst them, metallic nanoparticles have shown promise to fight cancer and improve patient's health. ${ }^{9-11}$ AgNPs demonstrated excellent properties for various applications, especially in biomedical applications. $^{12,13}$ AgNPs can treat cancer via alterations in cells' morphology, lower metabolic activity, and cell viability, increase oxidative stress, and increase the production of the DNA damaged reactive oxygen species (ROS). ${ }^{14}$ Asharani et al have studied the cellular and molecular mechanism of AgNPs' effects on two types of cancer cell lines, normal human lung cells, IMR-90, and human brain cancer cells, U251. ${ }^{15}$ AgNPs can adsorb cytosolic protein on their surface which influences the function of certain intracellular variables and regulates gene expression and pro-inflammatory cytokinesis. Another possible mechanism is the autophagy-induced cell death induced by AgNPs, a critical cellular degradation process ending with cell death at an elevated autophagy level. ${ }^{16}$ Researchers investigated the development of AgNPs for effective cancer treatment, investigation, and diagnosis. Different drugs, polymers, and nanomaterials can be conjugated and/or decorated with AgNPs to enhance their selectivity and efficiency toward other cancer cells. ${ }^{17,18}$ Various materials can be used to reduce silver nitrate and stabilize the formed AgNPs, such as trisodium citrate and sodium borohydride. Besides, polymeric materials could also develop and stabilize the AgNPs, eg, PEG, Chitosan, and cellulosic polymers. ${ }^{19-21}$ These materials stabilize the formed AgNPs and enhance and improve the characteristic activities of the produced AgNPs. Muhammad et al have shown the efficient anticancer activity of PEG capped methotrexate AgNPs against MCF-7 cell lines with reduced toxicity compared with methotrexate alone. ${ }^{22}$

The anticancer effect of albumin-coated AgNPs has been shown by Azizi et al on MDA-MB 231 human breast cancer cells. $^{23}$ The authors revealed higher cytotoxicity of AgNP-coated albumin against cancer cells than normal cells and apoptosis-based cell death, and decreased gland tumors in mice. Priya et al explored biogenic AgNPs/ Chitosan's anticancer action against human hepatocellular carcinoma HepG2 cells. $^{24}$ Chitosan-coated AgNPs enhanced invitro apoptosis activity and have a cytotoxic effect against HepG2 cell lines. Fahrenholtz et al explored the impact of AgNPs capped with PVP as a single agent or in conjunction with cisplatin against ovarian cancer. ${ }^{25}$ The authors delineate that AgNPs-PVP were extremely cytotoxic toward A2780, SKOV3 cell lines but less sensitive to OVCAR3. However, a combination with cisplatin showed a synergistic effect against A2780 and OVCAR3 cells.

Up to date and according to our search in the literature, the impact of EC-coated AgNPs against cancer cells has not been investigated earlier. This work aimed to study AgNPs-EC against MCF-7 breast cancer cell lines. AgNPs 
were prepared via the reduction of silver nitrate using EC as a reducing agent and stabilizer. The prepared AgNPsEC were characterized using UV-VIS spectrophotometry to confirm their formation. Moreover, AgNP size, charge, and morphology were also investigated. The invitro release of silver cations from AgNPs and physical stability was also evaluated for 3 months. AgNP-EC cytotoxicity to MCF-7 cells after 24-h treatment using an MTT assay was investigated. Besides, the effects of AgNP-EC MCF-7 proliferation, gene expression, and TNF- $\alpha$ production was estimated using real-time PCR and ELISA.

\section{Materials and Methods Materials}

Sodium chloride, sodium hydroxide, nitric acid, hydrochloric acid, sodium dihydrogen phosphate, and disodium hydrogen phosphate were purchased from Merck (Darmstadt, Germany). 2,2-Diphenyl-1-picrylhydrazyl (DPPH), MTT assay reagent, and human TNF- $\alpha$ antibodies were purchased from Sigma Aldrich (Steinheim, Germany). Cytokine-specific enzyme-linked immunosorbent assays were purchased from Santa Cruz Biotechnology Inc. (Bergheimer, Heidelberg, Germany). MCF-7 cells were purchased from American Type Culture Collection (ATCC, Manassas, VA, USA). All chemicals were of analytical grade. All glassware was washed with distilled water and dried at $40{ }^{\circ} \mathrm{C}$ in the oven.

\section{Synthesis of AgNPs-EC}

AgNPs with EC stabilization were prepared using the previously reported method by Abdellatif et al. ${ }^{26-28}$ Simply, EC standard $1 \%$ solution was prepared in distilled water, and $\mathrm{AgNO}_{3}$ aqueous solution $1 \mathrm{mM}$ was also prepared and adjusted for its $\mathrm{pH}(8.0)$ and ionic strength using $1 \mathrm{~mL} / \mathrm{mol} \mathrm{NaOH}$. The prepared $\mathrm{AgNO}_{3}$ solution was heated to boiling over a hot plate and kept stirring after addition of $2 \mathrm{~mL}$ of the prepared EC solution. After approximately 20-30 min, the solution's color changed to dark brown, indicating the formation of AgNPs-EC. The solution was cooled to laboratory temperature. Finally, the solution was filtered for 5 min via centrifugation at $3000 \mathrm{rpm}$ to extract concrete aggregate NPs. The remaining filtrate was kept at $4.0{ }^{\circ} \mathrm{C}$ for further NP analysis. ${ }^{29}$

\section{Characterization of AgNPs-EC UV-VIS Spectrophotometry}

To check the formation of AgNPs, we used UV-VIS scanning. A double beam spectrophotometer was used in the range of 300-600 wavelength (lambda 25 UV-VIS Spectrophotometer, PerkinElmer, Singapore) compared with a blank $\mathrm{AgNO}_{3}$ solution.

\section{Size and Charge}

As previously reported, the size and charge of the generated AgNPs-EC were calculated using a Malvern Zetasizer Nano Z.S. (Malvern Instruments GmbH, Herrenberg, Germany). ${ }^{26}$ Data were presented as the average of three different measurements of the same NP batch.

\section{Particle Morphology}

A transmission electron microscope was used to investigate AgNP-EC morphology (JEM-1230, Joel, Tokyo, Japan). AgNPs were fixed on carbon-coated 300-mesh copper grids, followed by drying overnight. AgNPs-EC were observed using 10-100 K magnification power and an accelerating voltage of $100 \mathrm{kV} .^{30,31} \mathrm{~A}$ scanning electron microscope (SEM) (Sputter coater, JOEL JFC-1300) was also used to investigate the AgNPs-EC. AgNP-EC solution was spotted onto a carbon-coated 300-mesh copper grid and left to stick with the carbon substrate. With the help of filter paper, excess solution was removed, followed by rinsing the copper grid twice in distilled water for $2-4$ s. Uranyl acetate $2 \%$ aqueous solution was then applied and the excess solution was removed; finally, the sample was left to dry at room temperature. ${ }^{30}$ A $10-100$ $\mathrm{K}$ magnification microscope power and an accelerating voltage of $100 \mathrm{kV}$ were used to display samples.

\section{Silver Ion Release}

Silver ions released from the prepared AgNPs-EC were carried out, as mentioned before by our research group. ${ }^{26,32}$ In vitro release was performed in double distilled water of about $100 \mathrm{~mL}$ for $48 \mathrm{~h}$. The amounts of silver cations released at different time points were calculated using inductively coupled plasma spectroscopy (ICP-OES, iCAP 6000, Thermo Scientific, USA) with an emission detector against a blank silver metal standard solution. Data were presented as the mean of three additional readings. 


\section{AgNP-EC Stability}

The physical stability of AgNP-EC dispersion was carried out at two different conditions, room temperature at 4.0 $\pm 0.5{ }^{\circ} \mathrm{C} .{ }^{33}$ Fresh samples were prepared and left in the conditions, as mentioned earlier, for 3 months. Afterward, samples were analyzed for their size, charge, and shape.

\section{Cell Cultures Incubation with AgNPs-EC}

The research was conducted on human tumor cell lines in the breast (Michigan Cancer Foundation-7 (MCF-7)). The cells were cultured with $10 \%$ fetal bovine serum in RPMI1640 solution containing antibiotics $(100 \mathrm{u} / \mathrm{mL}$ penicillin and $100 \mu \mathrm{g} / \mathrm{mL}$ streptomycin) and seeded in a 96-well plate at $1 \times 10^{4}$ cells/well density and incubated at $37^{\circ} \mathrm{C}$, $5 \% \mathrm{CO}_{2}$, for $24 \mathrm{~h}^{34}$ The MCF-7 cell lines were incubated with AgNPs-EC at different concentrations (0.1-200 $\mu \mathrm{M})$. The effect of AgNPs-EC on the viability of the MCF-7 cell lines was determined invitro. Cytotoxicity was studied using the CytoTox-Glo ${ }^{\text {TM }}$ Cytotoxicity Assay Kit (Promega, Madison, WI, USA). ${ }^{35}$ Then, various concentrations of AgNPs-EC $(0.1-20 \mu \mathrm{M})$ were incubated with MCF-7 cell-lines for $2 \mathrm{~h}$ following the methods by Abdellatif et al for all formulas. ${ }^{36}$ The medium was removed, and the cells were set at $4{ }^{\circ} \mathrm{C}$ for $1 \mathrm{~h}$ at 150 $\mu \mathrm{L} /$ well $10 \%$ trichloroacetic acid and subsequently rinsed three times with PBS pH 7.4. Wells in the dark at $37{ }^{\circ} \mathrm{C}$ were stained with $70 \mu \mathrm{L} /$ well $0.4 \%$ SRB for $12 \mathrm{~min}$. The unbound dye was removed, and the cells were washed with $1 \%$ acetic acid then air-dried for $24 \mathrm{~h}$. In a shaker, the dye was solubilized at $1600 \mathrm{rpm}$ for $5 \mathrm{~min}$ on $50 \mu \mathrm{L} /$ well $10 \mathrm{mM}$ Tris base (pH 7.4). An ELISA microplate reader spectroscopically was used to calculate the optical density (OD) of each well at $570 \mathrm{~nm}$ (EXL 800 USA). The inhibitory concentration was estimated at $50 \%\left(\mathrm{IC}_{50}\right)$ from an exponential viability curve versus the norms' concentration. The viabilities were selected for each compound by the variable Sigmaplot software (Systat Software Inc) as (A570 of samples/A570 not being treated) $\times 100$ and the amount $\mathrm{IC}_{50}$ (the concentration required to inhibit cell viability by $50 \%$ ) for each compound. To predict the test compounds' cell viability and growth effects, the data were taken and analyzed.

Quantitative real-time PCR was used to measure the mRNA expression with GAPDH as endogenous control as defined in previous studies. ${ }^{34} \mathrm{~A}$ miRNA isolation kit was used to test the total RNA (Thermo Fisher Scientific, Waltham, MA, USA). The Superscript First-Strand
cDNA synthesis kit (Sigma Aldrich, Schnelldorf, Germany) was used to reverse-transcribe the total RNA $(0.5-2 \mu \mathrm{g})$. TaqMan Gene Expression Assays quantified TNF- $\alpha$ mRNA expression (Thermo Fisher Scientific). Real-time PCR amplification and data capture have been performed using the Phase One Real-Time PCR method (Applied Biosystems) with an initial stage of $95{ }^{\circ} \mathrm{C}, 10$ min, a second step, at $95{ }^{\circ} \mathrm{C} / 17 \mathrm{sec}$, and $60{ }^{\circ} \mathrm{C}$ for $60 \mathrm{sec}$ (40 cycles). The target's mRNA level was normalized to GAPDH and compared to the control (untreated sample). The obtained data were analyzed using the $\Delta \Delta \mathrm{CT}$ method. ${ }^{37}$

\section{TNF- $\alpha$ ELISA}

The MCF-7 cell lines were incubated with different doses of AgNPs-EC $(0.1-20 \mu \mathrm{M})$ for $2 \mathrm{~h}$. The TNF- $\alpha$ in the culture medium was measured using the TNF- $\alpha$-specific ELISA in accordance with the instructions of the manufacturer (R\&D Systems, Minneapolis, MN, USA). The ELISA kit (Cayman Chemicals, Ann Arbor, MI, USA) was used in compliance with the manufacturer's instructions. They were using an automated microplate reader (Anthos Zenyth 3100 Multimode Detectors, Salzburg, Austria). The microtiter plate was read at $460 \mathrm{~nm}$ as stated in the literature. ${ }^{34}$

\section{Results \\ Preparation and Characterizations of AgNPs-EC}

A previous study performed by our group showed the applicability and usefulness of cellulosic polymers for efficient AgNP preparation. EC showed the best in terms of higher antioxidant and antibacterial activity as well as a superior physical stability, size, and charge. This is why EC was chosen in this study. ${ }^{26}$ Size analysis and zetapotential measurements showed that the produced AgNPsEC had a size of $150 \pm 5.1 \mathrm{~nm}$ (Figure 1A) and a charge of $-41.4 \pm 0.98 \mathrm{mV}$ (Figure 1B). A high value of zetapotential revealed the produced dispersion's stability, as discussed before from different studies. ${ }^{26}$ Morphological observations of the produced particles were done using SEM (Figure 1C) and TEM (Figure 1D). Both techniques revealed the non-aggregated nature of the produced AgNPs-EC as well as their spherical shape. Moreover, TEM demonstrated an NP size of $39.3 \pm 5.8 \mathrm{~nm}$, which confirms the DLS and SEM results. The lower size 


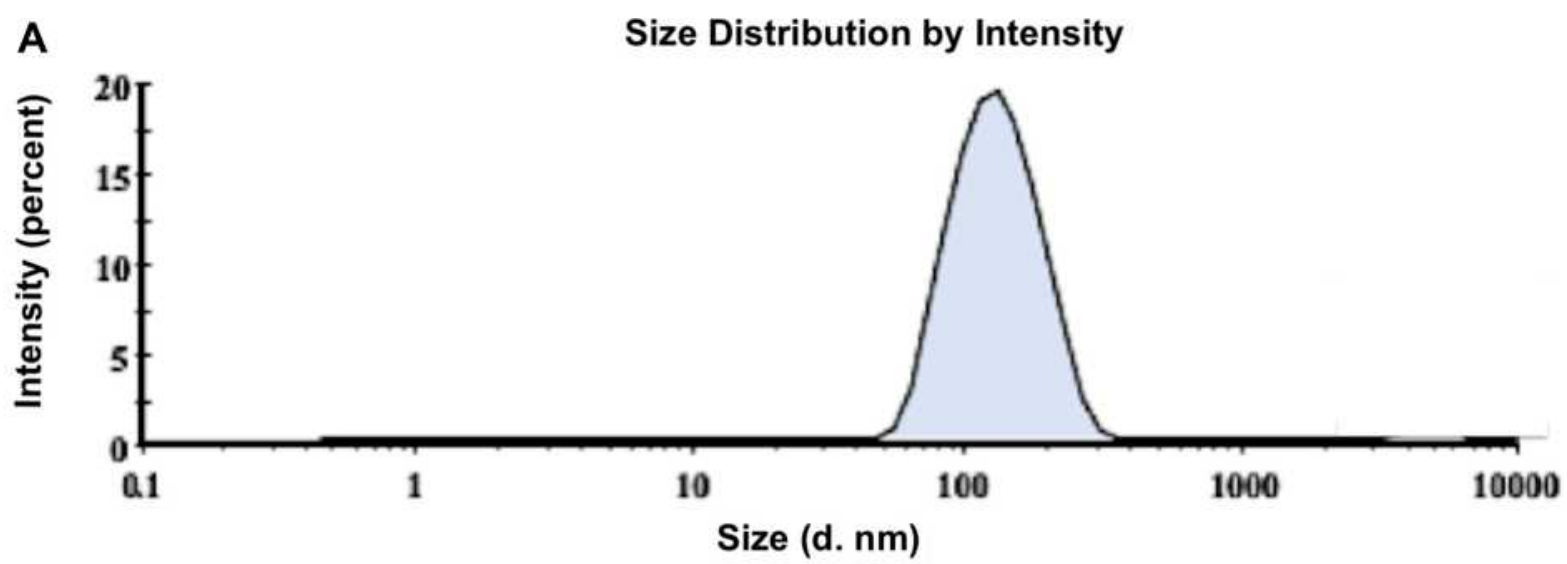

B

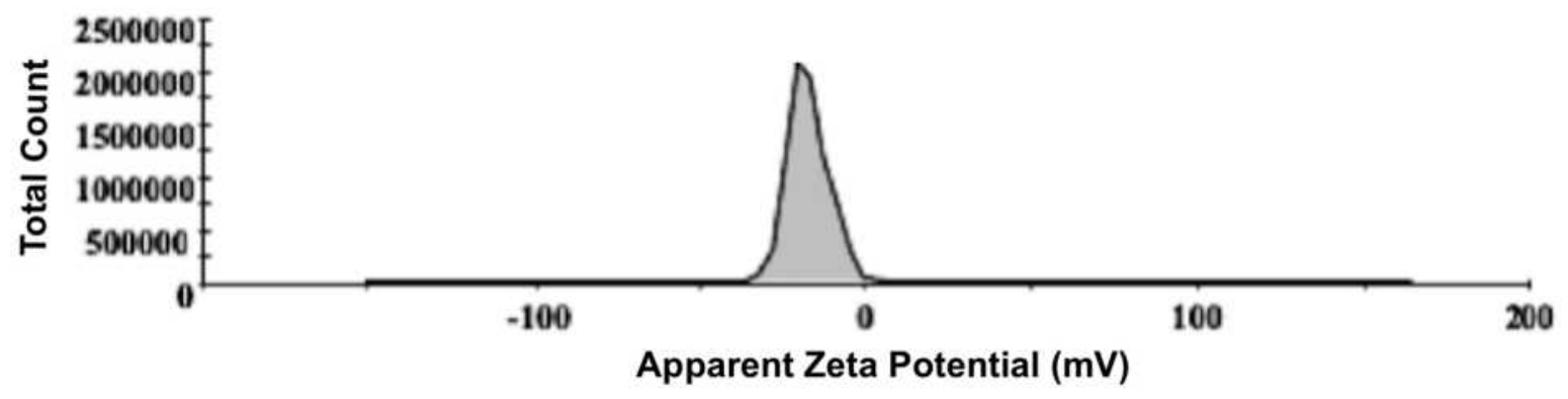

C
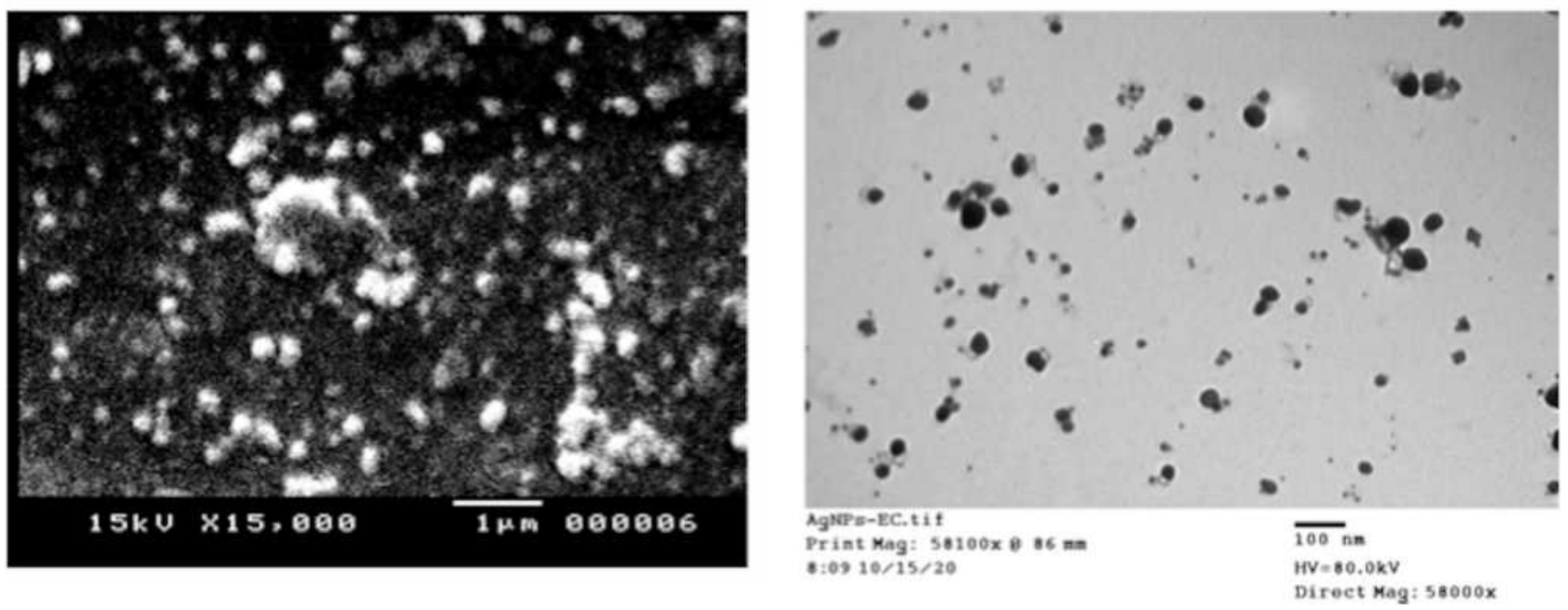

Figure I AgNPs reduced using ethyl cellulose. (A) Size distribution by the mean diameter as determined by DLS. (B) Apparent zeta-potential as determined by DLS. (C) SEM examination. (D) TEM observation.

observed via TEM compared with DLS is a common phenomenon observed by other researchers. ${ }^{30,38,39}$

The prepared AgNPs-EC was prepared using silver nitrate reduction via ethyl cellulose which acts as a reducing agent and stabilizing compound for efficient AgNP preparation with little aggregation, as investigated before by different researchers. ${ }^{26,40}$ This cellulosic derivative containing reducing groups and hydroxyl groups could 
offer the reducing properties for silver nitrate to produce silver NPs. The negatively charged EC facilitates the attraction of the positively charged silver cations to the polymeric chains followed by reduction with the exciting reducing groups. The successful synthesis includes two important steps; atom formation and polymerization of atoms as previously discussed. ${ }^{41}$ The negatively charged EC facilitates the attraction of the positively charged silver cations to the polymeric chains followed by reduction with the exciting reducing groups. The successful synthesis includes two important steps; atom formation and polymerization of atoms as previously discussed. ${ }^{42}$
Due to the effect of the surface plasmon resonance effect (SPR) of AgNPs and the successful reduction of silver ions to $\mathrm{Ag}^{+}$in the aqueous phase, the UV-VIS spectrophotometry analysis revealed a high absorption peak at a wavelength of about $391 \pm 0.16 \mathrm{~nm}^{43,44}$ (Figure 2A). The produced UV absorption spectrum is also an excellent indicator of efficient NP formulation reported by other researchers. ${ }^{26}$ Besides, the presence of a single peak delineates the symmetry of the produced NPs (Figure 1A). ${ }^{45}$ The study demonstrated EC's ability to form a coating layer around the NPs, hence protecting the NPs from aggregation and eventually higher physical stability. ${ }^{46}$
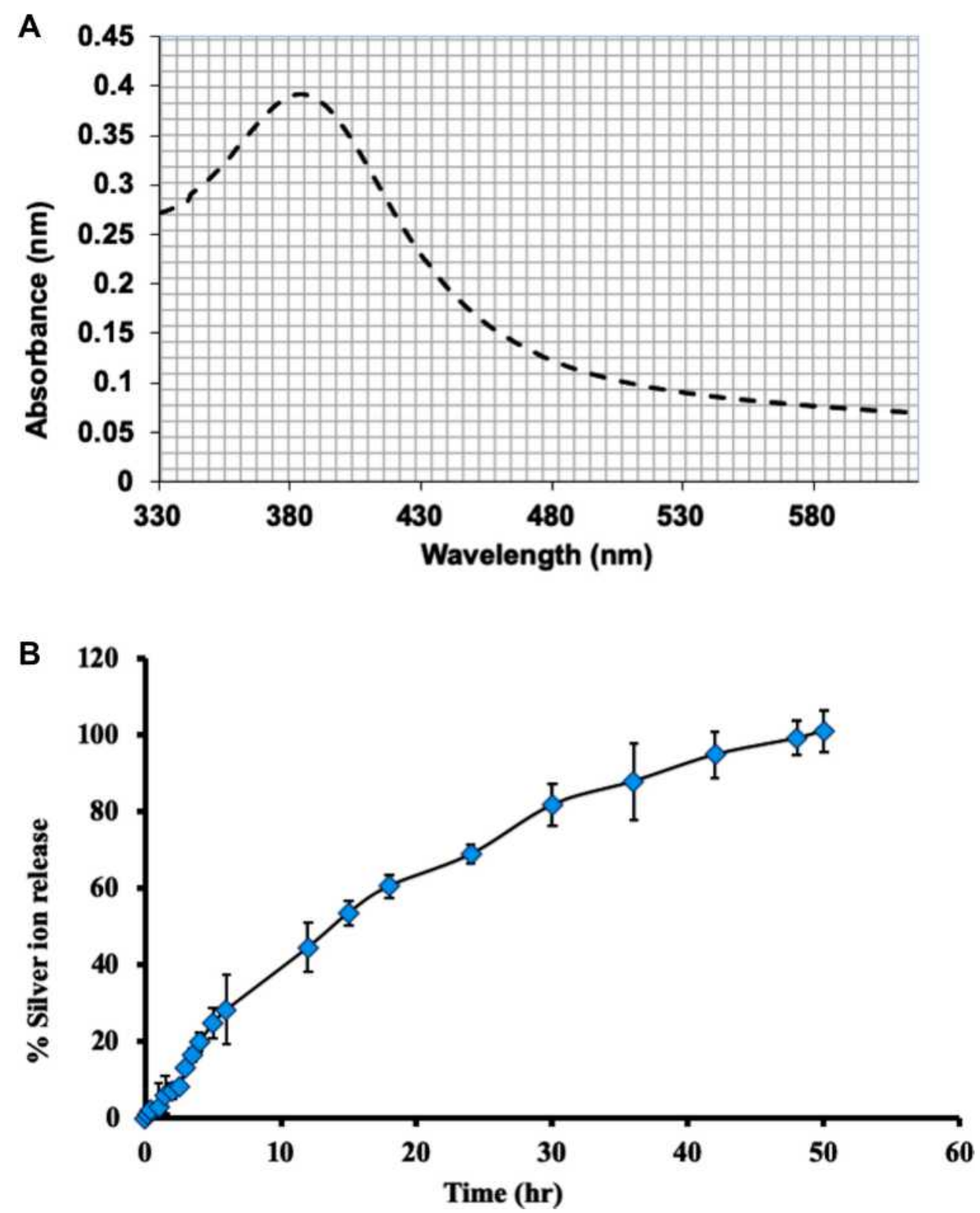

Figure 2 (A) UV-VIS spectra of AgNPs-EC, which showed the maximum absorbance at $391 \mathrm{~nm}$, refer to the surface plasmon resonance peak. (B) In vitro Ag ${ }^{+}$release from the prepared AgNPs-EC in deionized water $(n=3 \pm S D)$. 


\section{In vitro Silver lon Release}

A fundamental characteristic reflected in the generated nanoparticles' behavior is the release of silver ions from the prepared AgNPs (Figure 2B). Silver cations released were detected in an aqueous medium using ICP-OES. Initially, silver ions were calculated in AgNPs-EC and found to be $300.50 \pm 15.5 \mu \mathrm{M}$. The release profile showed a continuous phase for $48 \mathrm{~h}$. This release performance was attributed to EC's limited water solubility in water. ${ }^{47,48}$ Previous work has shown in our group the prolonged release of silver cations from AgNPs-EC compared with other AgNPs prepared using MC, HPMC, and PEG. ${ }^{26}$ It is also interesting to note the slow initial release of silver cations related to the shielding effect of polymer around NPs, affecting water ingress into the NP core. ${ }^{32}$ In other words, the cellulose fiber chains probably acted as a physical barrier to impede the silver cations release as demonstrated before. In addition, the hydroxyl groups within AgNPs-EC could also capture the released silver cations which finally restrict its release. ${ }^{49}$

\section{Physical Stability}

The physical stability of the developed AgNPs-EC was carried out 3 months at two different temperatures. Afterward, the size, charge, and morphology were performed and compared with freshly prepared particles. Morphological observations did not show any significant change in particle shape. Besides, a non-significant change in both size and charge was noticed, reflecting the higher physical stability of the produced NPs. Hence the prominent role of EC in the formulation and stability of AgNPs (Table 1).

\section{Incubation of AgNPs-EC with Cell Lines}

The cytotoxicity of AgNPs-EC was investigated in MCF-7 cells after $24 \mathrm{~h}$ using the MTT assay procedure. The AgNPs-EC were carried out using different concentrations $(0.1-200 \mu \mathrm{M})$. The cells have been incubated at a higher concentration of $200 \mu \mathrm{M}$ for $4 \mathrm{~h}$. AgNPs-EC, as determined by MTT assay, showed no toxicity to the cells (Figure 3). Based on the findings mentioned earlier by Yingying et al, we used this concentration. ${ }^{50}$ They noted that the toxicity of AgNPs-citrate increased as the concentration increased above $10 \mu \mathrm{g} / \mathrm{mL}$, while the concentration of $5 \mu \mathrm{g} / \mathrm{mL}$ AgNPs-citrate might be low toxicity.

After treatment with AgNPs-EC, we tested cell proliferation. Cell viability is not affected by the increased concentrations of AgNPs-EC (Figure 4). Control cells and AgNPs-EC treated cells in concentrations of 5 and $10 \mu \mathrm{M}$ for $4 \mathrm{~h}$, demonstrating the proliferation of cells treated with AgNPs-EC. Enhanced proliferation also underlines AgNPs-EC inhibitory effect on the differentiation of MCF-7 cells. In $10 \mu \mathrm{M}$ AgNPs-EC, cell viability decreased marginally compared to $5 \mu \mathrm{M}$ AgNP-EC-treated cells resulting from stopped proliferation due to increased $\mathrm{Ag}^{+}$concentration. These findings indicate that AgNPs-EC cytotoxicity function was primarily linked to the intracellular release of $\mathrm{Ag}^{+} .50$ The release of $\mathrm{Ag}^{+}$ions from nanosilver particles in aqueous solutions has been shown to lead to the mass leached or dissolved from its surface by one or two oxidized monolayers, depending on the size of the AgNPs-EC. This process is much more comfortable at low concentrations, and a high concentration of $\mathrm{Ag}^{+}$could be released, causing cell death. And vice versa, the elevated concentration of AgNPs is challenging to be ionized. $^{51}$

MCF-7 cells were pretreated for $2 \mathrm{~h}$ with AgNPs-EC $(0.1-10 \mu \mathrm{M})$, and at the dose used there was no cytotoxic effect of AgNPs-EC. The TNF- $\alpha$ mRNA level was measured using a susceptible and exact quantitative RT-PCR method and values were compared with the control. To assess the effect of inhibition in protein level in gene expression, TNF- $\alpha$-specific ELISA culture supernatants have been tested for TNF- $\alpha$ protein. As demonstrated in Figure 5A, the result showed that pretreatment with a concentration of $20 \mu \mathrm{M}$ AgNPs-EC showed a reduction in the TNF- $\alpha$ mRNA level compared to a lower concentration of AgNPs-EC (0.1, 0.2, 0.5, 5, and $10 \mu \mathrm{M}$ ) (Figure $5 \mathrm{~B})$. The TNF- $\alpha$ production in the culture supernatant in MCF-7 stimulated by pretreatment of $0.1-20 \mu \mathrm{M}$ AgNPsEC decreased significantly. In cultures treated with $20 \mu \mathrm{M}$ AgNPs-EC, maximum removal was observed.

Table I Characterization of Freshly Prepared AgNPs-EC and After 3 Months of Storage

\begin{tabular}{|l|l|l|l|l|l|}
\hline Prepared AgNPs-EC & Size $\mathbf{( n m})$ & Zeta-Potential & $\mathbf{p H}$ & Wavelength $\mathbf{( n m})$ & Physical Observations \\
\hline Freshly prepared & $150 \pm 5.1$ & $-41.4 \pm 0.98$ & 7.1 & $391 \pm 0.16$ & Dark brown without any precipitate \\
\hline Three months storage & $159 \pm 3.2$ & $-38.23 \pm 1.23$ & 7.32 & $391 \pm 0.8$ & No remarkable change, without precipitate \\
\hline
\end{tabular}




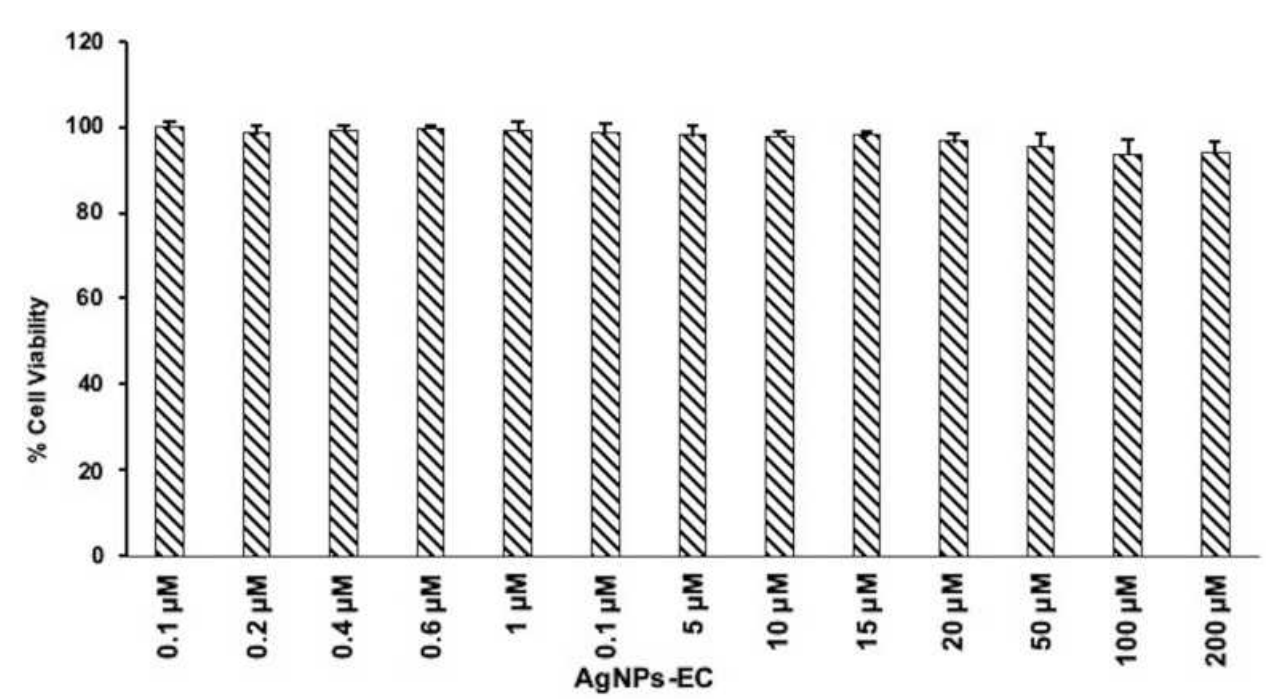

Figure 3 Effects of AgNPs-EC on \% viability of MCF-7. Cell viability of MCF-7 cells treated with a concentration of AgNPs-EC $(0.1-200 \mu M)$, incubation for $24 \mathrm{~h}$, and then cytotoxicity examined using the MTT assay.

\section{Discussion}

Green synthesis is a new area of bio-nanotechnology that offers economic and environmental advantages over traditional physical and chemical methods. Non-toxic safe reagents such as EC are eco-friendly and biosafe. Plant extracts have been investigated for the synthesis of metal oxide nanoparticles as safe and non-toxic nanoparticles. ${ }^{52,53}$ The anticancer outcome of AgNPs reduced with EC was investigated in this study, and their impact on TNF- $\alpha$ levels was also investigated. ${ }^{54}$ A sensitive and specific quantitative RT-PCR technique has quantified the TNF- $\alpha$ mRNA. Results indicated a noticeable considerable decline in the TNF- $\alpha$ mRNA levels. This reduction in the level of TNF- $\alpha$ may have a positive effect on breast cancer treatment since it is a pro-inflammatory cytokine that is regulated in cancer of this type. It is also considered an essential performer in tumor induction, promotion, angiogenesis, and metastasis. ${ }^{55}$ The elevated TNF- $\alpha$ levels are correlated to breast cancer recurrence, progression, and metastasis. ${ }^{56}$ This means the suppression of TNF- $\alpha$ could reduce the inflammation associated with breast cancer and improves the chemotherapeutic effect. It could help in preventing or reducing the resistance to the therapy in breast cancer. ${ }^{3}$

Increased endogenous TNF- $\alpha$ may be documented to promote tumor invasion by downregulating progesterone receptor expression in breast cancer. ${ }^{57}$ The AgNPs bind non-specifically to TNFR1 when tumor cells are exposed

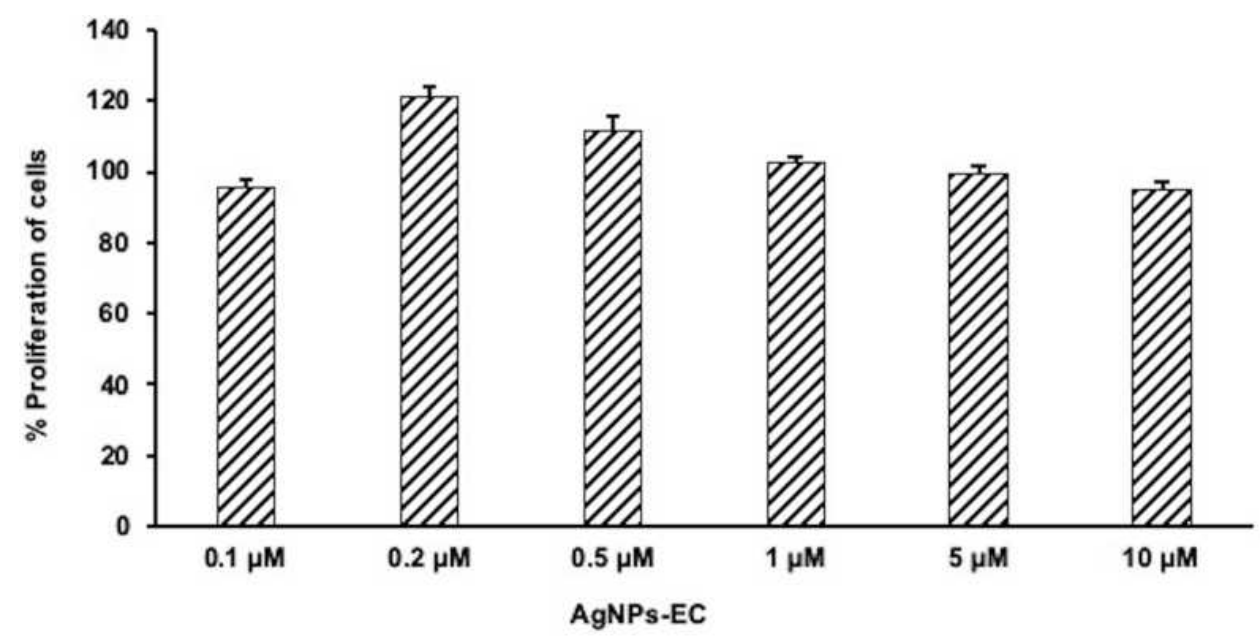

Figure 4 Effects of AgNPs-EC on the proliferation of MCF-7. Cell viability of MCF-7 cells treated first with a concentration of $0.1-10 \mu M$. 

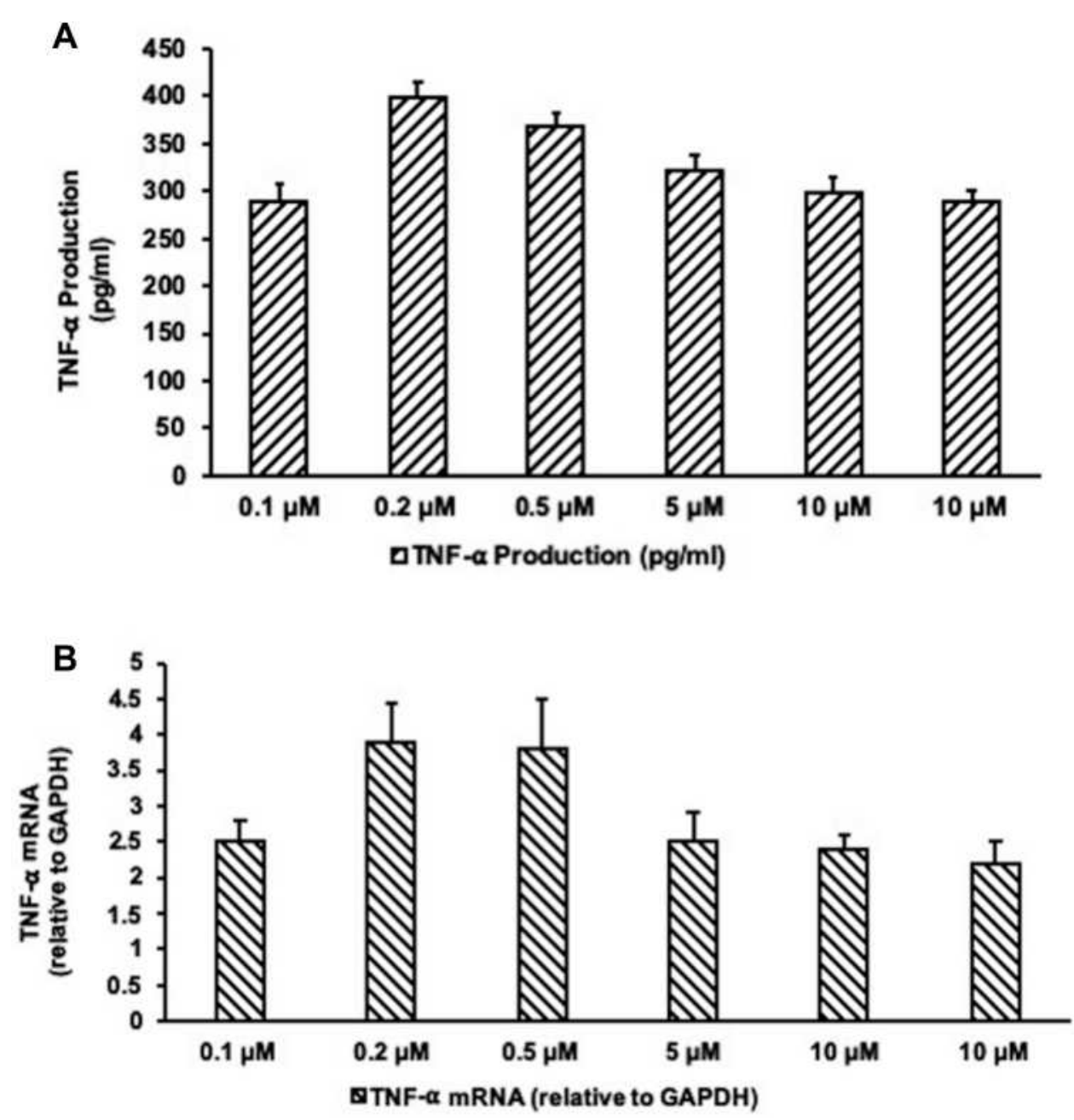

Figure 5 Gene expression and production of TNF- $\alpha$. (A) Effect of AgNPs-EC on the gene expression of TNF- $\alpha$. (B) Effect of AgNPs-EC on the output of TNF- $\alpha$ in MCF-7 cells.

to both TNF- $\alpha$ and AgNPs. Specifically, TNF- $\alpha$ binds to the same receptor, forming a complex of TNFR1-TNF- $\alpha$ AgNPs that enter the cells via endocytosis mediated by TNF- $\alpha$ 's receptors. The TNF- $\alpha$ receptor is released and causes apoptosis. Receptors which still bind to AgNPs caused disruption to the receptor's profile, molecular weight, and features, which caused the disruption in its normal pathway for the recycling of cell membrane, followed by less TNFR1 within and within the cell membrane. This molecular mechanism explains how TNFR1 would play a role in enhancing the cellular absorption of AgNPs because TNF- $\alpha$-induced apoptosis would be reduced. The mechanism explains that the AgNPsTNFR1 complex obstructs the receptors' re-expression pathway on the cell membrane, triggering a decrease in the transduction of the TNF- $\alpha$ signal and its apoptotic effect. $^{8}$
In our study, the cytotoxic effect of the prepared AgNPsEC was assessed on MCF-7 after $2 \mathrm{~h}$ via the MTT assay procedure. Different concentrations of AgNPs-EC did not affect the cell viability. These findings indicate that AgNPEC cytotoxicity function was nearly neglected for the normal cell and can be considered safe. It acts only via decreasing the TNF- $\alpha$ responsible for the proliferation, progression, and tumor metastasis. However, there is no full understanding of the mechanism(s) associated with AgNPs cytotoxicity. To explain the cytotoxicity, AgNP-EC interaction with the mitochondrial inner membrane thiol groups is agreed to occur. They proposed that this contributes to the antioxidant defense system being depleted, which leads to the development of ROS. The result of ROS accumulation is an inflammatory response. Mitochondria destruction was triggered by the cells' inflammatory response, which caused apoptogenic factors that induced cell death. ${ }^{58}$ 
AgNPs generate different biochemical pathways, including ROS-mediated mitochondrial dysfunction, DNA damage, and apoptosis, that are related to the enhanced anticancer activities in MCF-7 cells. ${ }^{53,59}$ The results we obtained in this study are in line with the findings of researchers in previous examinations. Mugade et al bioengineered (mannan sulfate-capped AgNPs) to downregulate TNF- $\alpha$ and IL- 6 expression in rats. ${ }^{60}$ Wong et al also studied the AgNPs' anti-inflammatory activity and found that AgNPs were able to decrease the TNF- $\alpha$ production. ${ }^{61}$ Furthermore, the study was mediated by Liu et al demonstrating that dendrimer encapsulation AgNPs (AgNPs-DNC) could suppress TNF- $\alpha$ and IL-6 production invitro. ${ }^{62}$ These findings show that AgNP-EC anticancer potential activity could be linked to apoptosis initiation by inhibiting the activation and nuclear translocation of mRNA and protein expression of TNF- $\alpha$ in MCF-7 cells. AgNPs-EC have a strong effect on inflammation and toxic effect promoted by TNF- $\alpha$.

On the other hand, the toxic effect of AgNPs has been indicated in several invivo studies. This effect is related to many variables such as size, concentration, route of administration, and internal usage. AgNPs are considered a doubleedged sword. In this study, the used concentration of AgNPsEC was found to be non-toxic to the normal cells, which is a good sign for safety of these cells. According to Fehaid and Taniguchi, these prepared nanoparticles are not toxic to normal cells due to their relatively large diameter. The cytotoxicity of AgNPs is size-related. A small size of about $10 \mathrm{~nm}$ is easily ionized, releasing $\mathrm{Ag}^{+}$which is toxic to the cell. However, cell-based absorption of $150 \mathrm{~nm}$ particles prepared in this research can occur by endocytosis of their spheres. When held in endosomes and not easily ionized they are not readily accessible, which results in a low cytotoxic effect. ${ }^{63}$

However, to determine their potential for anticancer activity, clinical studies are required in the future. Biologically synthesized AgNPs-EC were studied for the treatment of cell line breast cancer (MCF-7). The research indicates that these AgNPs-EC are non-toxic and successfully penetrate cancer cells within the studied range of concentrations (1-100 $\mu \mathrm{g} /$ $\mathrm{mL}$ ). The previous study also discussed that AgNPs could serve as inert medical preparation platforms and as active reagents capable of affecting cell systems' functions bind to the endosomal, exosomes, and lysosome depending on size and probably charge. ${ }^{64}$ These studies are supported by Hussain et al's study of toxic response in rat-liver cells BRL $3 \mathrm{~A}$ of AgNPs (15 and $100 \mathrm{~nm}$ ). In this type of cell, they discovered the toxicity of AgNPs. They also determined that mitochondrial function significantly decreased at $5-50 \mu \mathrm{g} / \mathrm{mL}$ in cells subjected to AgNPs. ${ }^{65}$

\section{Conclusions}

AgNPs-EC acted as a TNF- $\alpha$ inhibitor at substantial levels to support the theory regarding the suppression of cancer by physiological and biochemical signals. These findings play an important potential role in uncovering novel pathways for cancer prevention and care.

\section{Acknowledgments}

The authors extend their appreciation to the Deputyship for Research \& Innovation, Ministry of Education, Saudi Arabia for funding this research work through project number QU-IF-1-2-1. The authors also thank the technical support of Qassim University.

\section{Disclosure}

The authors declare no conflicts of interest in this work.

\section{References}

1. Cruceriu D, Baldasici O, Balacescu O, Berindan-Neagoe I. The dual role of tumor necrosis factor-alpha (TNF-alpha) in breast cancer: molecular insights and therapeutic approaches. Cell Oncol (Dordr). 2020;43(1):1-18. doi:10.1007/s13402-019-00489-1

2. Anderson GM, Nakada MT, DeWitte M. Tumor necrosis factor-alpha in the pathogenesis and treatment of cancer. Curr Opin Pharmacol. 2004;4(4):314-320. doi:10.1016/j.coph.2004.04.004

3. Mercogliano MF, Bruni S, Elizalde PV, Schillaci R. Tumor necrosis factor alpha blockade: an opportunity to tackle breast cancer. Front Oncol. 2020;10:584.

4. Zhou XL, Fan W, Yang G, Yu MX. The clinical significance of PR, ER, NF- kappa B, and TNF- alpha in breast cancer. Dis Markers. 2014;2014:494581. doi:10.1155/2014/494581

5. O'Riordan KJ, Huang IC, Pizzi M, et al. Regulation of nuclear factor kappaB in the hippocampus by group I metabotropic glutamate receptors. $J$ Neurosci. 2006;26(18):4870-4879. doi:10.1523/ JNEUROSCI.4527-05.2006

6. Wenliang T, Luo X, Li W, et al. TNF-alpha is a potential therapeutic target to overcome sorafenib resistance in hepatocellular carcinoma. EBioMedicine. 2019;40:446-456. doi:10.1016/j. ebiom.2018.12.047

7. Wu X, Wu MY, Jiang M, et al. TNF-alpha sensitizes chemotherapy and radiotherapy against breast cancer cells. Cancer Cell Int. 2017;17 (1):13. doi:10.1186/s12935-017-0382-1

8. Fehaid A, Taniguchi A. Silver nanoparticles reduce the apoptosis induced by tumor necrosis factor-alpha. Sci Technol Adv Mater. 2018;19(1):526-534. doi:10.1080/14686996.2018.1487761

9. Chugh H, Sood D, Chandra I, Tomar V, Dhawan G, Chandra R. Role of gold and silver nanoparticles in cancer nano-medicine. Artif Cells Nanomed Biotechnol. 2018;46(sup1):1210-1220. doi:10.1080/ 21691401.2018.1449118

10. Huy TQ, Huyen PTM, Le AT, Tonezzer M. Recent advances of silver nanoparticles in cancer diagnosis and treatment. Anticancer Agents Med Chem. 2020;20(11):1276-1287. doi:10.2174/ 1871520619666190710121727 
11. Maiyo F, Singh M. Selenium nanoparticles: potential in cancer gene and drug delivery. Nanomedicine (Lond). 2017;12(9):1075-1089. doi:10.2217/nnm-2017-0024

12. Gurunathan S, Park JH, Han JW, Kim JH. Comparative assessment of the apoptotic potential of silver nanoparticles synthesized by Bacillus tequilensis and Calocybe indica in MDA-MB-231 human breast cancer cells: targeting p53 for anticancer therapy. Int J Nanomedicine. 2015;10:4203-4222. doi:10.2147/IJN.S83953

13. Li WR, Xie XB, Shi QS, Zeng HY, Ou-Yang YS, Chen YB. Antibacterial activity and mechanism of silver nanoparticles on Escherichia coli. Appl Microbiol Biotechnol. 2010;85(4):1115-1122. doi:10.1007/s00253-009-2159-5

14. AshaRani PV, Low Kah Mun G, Hande MP, Valiyaveettil S. Cytotoxicity and genotoxicity of silver nanoparticles in human cells. ACS Nano. 2009;3(2):279-290. doi:10.1021/nn800596w

15. Asharani P, Sethu S, Lim HK, Balaji G, Valiyaveettil S, Hande MP. Differential regulation of intracellular factors mediating cell cycle, DNA repair and inflammation following exposure to silver nanoparticles in human cells. Genome Integr. 2012;3(1):2. doi:10.1186/20419414-3-2

16. Lin J, Huang $\mathrm{Z}$, $\mathrm{Wu} \mathrm{H}$, et al. Inhibition of autophagy enhances the anticancer activity of silver nanoparticles. Autophagy. 2014;10 (11):2006-2020. doi:10.4161/auto.36293

17. Yang L, Gao Y, Liu J, et al. Silver-coated nanoparticles combined with doxorubicin for enhanced anticancer therapy. $J$ Biomed Nanotechnol. 2018;14(2):312-320. doi:10.1166/jbn.2018.2481

18. Capanema NSV, Carvalho IC, Mansur AAP, Carvalho SM, Lage AP, Mansur HS. Hybrid hydrogel composed of carboxymethylcellulose-silver nanoparticles-doxorubicin for anticancer and antibacterial therapies against melanoma skin cancer cells ACS Appl Nano Mater. 2019;2(11):7393-7408. doi:10.1021/ acsanm.9b01924

19. Kumar S, Meena VK, Hazari PP, Sharma RK. PEG coated and doxorubicin loaded multimodal Gadolinium oxide nanoparticles for simultaneous drug delivery and imaging applications. Int J Pharm. 2017;527(1-2):142-150. doi:10.1016/j.ijpharm.2017.05.027

20. Venkatesan J, Lee JY, Kang DS, et al. Antimicrobial and anticancer activities of porous chitosan-alginate biosynthesized silver nanoparticles. Int J Biol Macromol. 2017;98:515-525. doi:10.1016/ j.ijbiomac.2017.01.120

21. Parthasarathy A, Vijayakumar S, Malaikozhundan B, et al. Chitosancoated silver nanoparticles promoted antibacterial, antibiofilm, wound-healing of murine macrophages and antiproliferation of human breast cancer MCF 7 cells. Polym Test. 2020;90:106675. doi:10.1016/j.polymertesting.2020.106675

22. Muhammad Z, Raza A, Ghafoor S, et al. PEG capped methotrexate silver nanoparticles for efficient anticancer activity and biocompatibility. Eur J Pharm Sci. 2016;91:251-255. doi:10.1016/j. ejps.2016.04.029

23. Azizi M, Ghourchian H, Yazdian F, Bagherifam S, Bekhradnia S, Nystrom B. Anti-cancerous effect of albumin coated silver nanoparticles on MDA-MB 231 human breast cancer cell line. Sci Rep. 2017;7(1):5178. doi:10.1038/s41598-017-05461-3

24. Priya K, Vijayakumar M, Janani B. Chitosan-mediated synthesis of biogenic silver nanoparticles (AgNPs), nanoparticle characterisation and in vitro assessment of anticancer activity in human hepatocellular carcinoma HepG2 cells. Int J Biol Macromol. 2020;149:844-852. doi:10.1016/j.ijbiomac.2020.02.007

25. Fahrenholtz CD, Swanner J, Ramirez-Perez M, Singh RN. Heterogeneous responses of ovarian cancer cells to silver nanoparticles as a single agent and in combination with cisplatin. J Nanomater. 2017;2017:5107485. doi:10.1155/2017/5107485

26. Abdellatif AAH, Alturki HNH, Tawfeek HM. Different cellulosic polymers for synthesizing silver nanoparticles with antioxidant and antibacterial activities. Sci Rep. 2021;11(1):84. doi:10.1038/s41598020-79834-6
27. Kolarova K, Samec D, Kvitek O, Reznickova A, Rimpelova S, Svorcik V. Preparation and characterization of silver nanoparticles in methyl cellulose matrix and their antibacterial activity. Jpn J Appl Phys. 2017;56(6S1):06GG09. doi:10.7567/JJAP.56.06GG09

28. Suwan T, Khongkhunthian S, Okonogi S. Silver nanoparticles fabricated by reducing property of cellulose derivatives. Drug Discov Ther. 2019;13(2):70-79. doi:10.5582/ddt.2019.01021

29. Elbakry A, Zaky A, Liebl R, Rachel R, Goepferich A, Breunig M. Layer-by-layer assembled gold nanoparticles for siRNA delivery. Nano Lett. 2009;9(5):2059-2064. doi:10.1021/n19003865

30. Tawfeek HM, Abdellatif AAH, Abdel-Aleem JA, Hassan YA, Fathalla D. Transfersomal gel nanocarriers for enhancement the permeation of lornoxicam. J Drug Deliv Sci Technol. 2020;56:101540. doi:10.1016/j.jddst.2020.101540

31. Sun Q, Cai X, Li J, Zheng M, Chen Z, Yu C-P. Green synthesis of silver nanoparticles using tea leaf extract and evaluation of their stability and antibacterial activity. Colloids Surf a Physicochem Eng Asp. 2014;444:226-231. doi:10.1016/j.colsurfa.2013.12.065

32. Fortunati E, Latterini L, Rinaldi S, Kenny JM, Armentano I. PLGA/ Ag nanocomposites: in vitro degradation study and silver ion release. J Mater Sci Mater Med. 2011;22(12):2735-2744. doi:10.1007/ s10856-011-4450-0

33. Onuki Y, Machida Y, Yokawa T, Seike C, Sakurai S, Takayama K. Magnetic resonance imaging study on the physical stability of menthol and diphenhydramine cream for the treatment of chronic kidney disease-associated pruritus. Chem Pharm Bull (Tokyo). 2015;63(6):457-462. doi:10.1248/cpb.c15-00192

34. Abdellatif AAH, Rasheed Z, Alhowail AH, et al. Silver citrate nanoparticles inhibit PMA-induced TNFalpha expression via deactivation of NF-kappaB activity in human cancer cell-lines, MCF-7. Int J Nanomedicine. 2020;15:8479-8493. doi:10.2147/IJN.S274098

35. Rasheed Z, Rasheed N, Al-Shaya O. Epigallocatechin-3-O-gallate modulates global microRNA expression in interleukin-1betastimulated human osteoarthritis chondrocytes: potential role of EGCG on negative co-regulation of microRNA-140-3p and ADAMTS5. Eur J Nutr. 2018;57(3):917-928. doi:10.1007/s00394016-1375-X

36. Abdellatif AAH, Ibrahim MA, Amin MA, et al. Cetuximab conjugated with octreotide and entrapped calcium alginate-beads for targeting somatostatin receptors. Sci Rep. 2020;10(1):4736. doi:10.1038/s41598-020-61605-y

37. Pfaffl MW. A new mathematical model for relative quantification in real-time RT-PCR. Nucleic Acids Res. 2001;29(9):e45. doi:10.1093/ nar/29.9.e45

38. Ong HX, Traini D, Cipolla D, et al. Liposomal nanoparticles control the uptake of ciprofloxacin across respiratory epithelia. Pharm Res. 2012;29(12):3335-3346. doi:10.1007/s11095-012-0827-0

39. Said-Elbahr R, Nasr M, Alhnan MA, Taha I, Sammour O. Nebulizable colloidal nanoparticles co-encapsulating a COX-2 inhibitor and a herbal compound for treatment of lung cancer. Eur J Pharm Biopharm. 2016;103:1-12. doi:10.1016/j.ejpb.2016.03.025

40. Xu Y, Li S, Yue X, Lu W. Review of silver nanoparticles (AgNPs)-cellulose antibacterial composites. BioResources. 2018;13 (1):2150-2170.

41. Hebeish AA, El-Rafie MH, Abdel-Mohdy FA, Abdel-Halim ES, Emam HE. Carboxymethyl cellulose for green synthesis and stabilization of silver nanoparticles. Carbohydr Polym. 2010;82 (3):933-941. doi:10.1016/j.carbpol.2010.06.020

42. Goia DV. Preparation and formation mechanisms of uniform metallic particles in homogeneous solutions. J Mater Chem. 2004;14 (4):451-458. doi:10.1039/b311076a

43. Hajji S, Salem RB, Hamdi M, et al. Nanocomposite films based on chitosan-poly(vinyl alcohol) and silver nanoparticles with high antibacterial and antioxidant activities. Process Saf Environ Protect. 2017;111:112-121. doi:10.1016/j.psep.2017.06.018 
44. Zielińska A, Skwarek E, Zaleska A, Gazda M, Hupka J. Preparation of silver nanoparticles with controlled particle size. Procedia Chem. 2009;1(2):1560-1566. doi:10.1016/j.proche.2009.11.004

45. Pal S, Tak YK, Song JM. Does the antibacterial activity of silver nanoparticles depend on the shape of the nanoparticle? A study of the gram-negative bacterium Escherichia coli. Appl Environ Microbiol. 2007;73(6):1712-1720. doi:10.1128/AEM.02218-06

46. Liu H, Wang D, Song Z, Shang S. Preparation of silver nanoparticles on cellulose nanocrystals and the application in electrochemical detection of DNA hybridization. Cellulose. 2010;18(1):67-74. doi:10.1007/s10570-010-9464-0

47. Duarte AR, Gordillo MD, Cardoso MM, Simplicio AL, Duarte CM. Preparation of ethyl cellulose/methyl cellulose blends by supercritical antisolvent precipitation. Int $J$ Pharm. 2006;311(1-2):50-54. doi:10.1016/j.ijpharm.2005.12.010

48. Raut NS, Somvanshi S, Jumde AB, Khandelwal HM, Umekar MJ, Kotagale NR. Ethyl cellulose and hydroxypropyl methyl cellulose buoyant microspheres of metoprolol succinate: influence of $\mathrm{pH}$ modifiers. Int J Pharm Investig. 2013;3(3):163-170. doi:10.4103/ 2230-973X.119235

49. Feng J, Shi Q, Li W, et al. Antimicrobial activity of silver nanoparticles in situ growth on TEMPO-mediated oxidized bacterial cellulose. Cellulose. 2014;21(6):4557-4567. doi:10.1007/s10570014-0449-2

50. Yingying X, Wang L, Bai R, Zhang T, Chen C. Silver nanoparticles impede phorbol myristate acetate-induced monocyte-macrophage differentiation and autophagy. Nanoscale. 2015;7(38):16100-16109. doi:10.1039/C5NR04200C

51. Kedziora A, Speruda M, Krzyzewska E, Rybka J, Lukowiak A, Bugla-Ploskonska G. Similarities and differences between silver ions and silver in nanoforms as antibacterial agents. Int $J$ Mol Sci. 2018;19(2):444. doi:10.3390/ijms 19020444

52. Mtibe A, Mokhothu TH, John MJ, Mokhena TC, Mochane MJ. Fabrication and characterization of various engineered nanomaterials. In: Handbook of Nanomaterials for Industrial Applications. 2018:151-171.

53. De Matteis V, Rizzello L, Ingrosso C, et al. Cultivar-dependent anticancer and antibacterial properties of silver nanoparticles synthesized using leaves of different olea europaea trees. Nanomaterials (Basel). 2019;9(11):1544. doi:10.3390/nano9111544

54. Alkhulaifi MM, Alshehri JH, Alwehaibi MA, et al. Green synthesis of silver nanoparticles using Citrus limon peels and evaluation of their antibacterial and cytotoxic properties. Saudi J Biol Sci. 2020;27 (12):3434-3441. doi:10.1016/j.sjbs.2020.09.031
55. Esquivel-Velazquez M, Ostoa-Saloma P, Palacios-Arreola MI, NavaCastro KE, Castro JI, Morales-Montor J. The role of cytokines in breast cancer development and progression. J Interferon Cytokine Res. 2015;35(1):1-16. doi:10.1089/jir.2014.0026

56. Liu W, Lu X, Shi P, et al. TNF-alpha increases breast cancer stem-like cells through up-regulating TAZ expression via the non-canonical NF-kappaB pathway. Sci Rep. 2020;10(1):1804. doi:10.1038/s41598-020-58642-y

57. Martinez-Reza I, Diaz L, Garcia-Becerra R. Preclinical and clinical aspects of TNF-alpha and its receptors TNFR1 and TNFR2 in breast cancer. J Biomed Sci. 2017;24(1):90. doi:10.1186/s12929-017-0398-9

58. Chen X, Schluesener HJ. Nanosilver: a nanoproduct in medical application. Toxicol Lett. 2008;176(1):1-12. doi:10.1016/j. toxlet.2007.10.004

59. Ullah I, Khalil AT, Ali M, et al. Green-synthesized silver nanoparticles induced apoptotic cell death in MCF-7 breast cancer cells by generating reactive oxygen species and activating caspase 3 and 9 enzyme activities. Oxid Med Cell Longev. 2020;2020:1215395. doi:10.1155/2020/1215395

60. Mugade M, Patole M, Pokharkar V. Bioengineered mannan sulphate capped silver nanoparticles for accelerated and targeted wound healing: physicochemical and biological investigations. Biomed Pharmacother. 2017;91:95-110. doi:10.1016/j.biopha.2017.04.017

61. Wong KK, Cheung SO, Huang L, et al. Further evidence of the anti-inflammatory effects of silver nanoparticles. ChemMedChem. 2009;4(7):1129-1135. doi:10.1002/cmdc.200900049

62. Liu X, Hao W, Lok CN, Wang YC, Zhang R, Wong KK. Dendrimer encapsulation enhances anti-inflammatory efficacy of silver nanoparticles. J Pediatr Surg. 2014;49(12):1846-1851. doi:10.1016/ j.jpedsurg.2014.09.033

63. Fehaid A, Taniguchi A. Size-dependent effect of silver nanoparticles on the tumor necrosis factor alpha-induced DNA damage response. Int J Mol Sci. 2019;20(5):1038. doi:10.3390/ijms20051038

64. Kulandaivelu B, Gothandam KM. Cytotoxic effect on cancerous cell lines by biologically synthesized silver nanoparticles. Braz Arch Biol Technol. 2016;59:e16150529. doi:10.1590/1678-4324-2016150529

65. Hussain SM, Hess KL, Gearhart JM, Geiss KT, Schlager JJ. In vitro toxicity of nanoparticles in BRL 3A rat liver cells. Toxicol in Vitro. 2005;19(7):975-983. doi:10.1016/j.tiv.2005.06.034

\section{Publish your work in this journal}

Drug Design, Development and Therapy is an international, peerreviewed open-access journal that spans the spectrum of drug design and development through to clinical applications. Clinical outcomes, patient safety, and programs for the development and effective, safe, and sustained use of medicines are a feature of the journal, which has also been accepted for indexing on PubMed Central. The manuscript management system is completely online and includes a very quick and fair peer-review system, which is all easy to use. Visit http://www. dovepress.com/testimonials.php to read real quotes from published authors. 